\title{
First report of IMI-1-producing colistin-resistant Enterobacter clinical isolate in Ireland, March 2013
}

T W Boo (teck.boo@hse.ie) ${ }^{1,2}$, N 0’Connell3, L Power ${ }^{3}$, M 0’Connor4, J King ${ }^{1}$, E McGrath ${ }^{1}$, R Hill5, K L Hopkins ${ }^{5}$, N Woodford5

1. Department of Medical Microbiology, Galway University Hospitals, HSE West, Ireland

2. Discipline of Bacteriology, School of Medicine, National University of Ireland Galway, Ireland

3. Department of Clinical Microbiology, Mid-western Regional Hospital, Limerick, HSE West, Ireland

4. Department of Geriatric Medicine, Mid-western Regional Hospital, Limerick, HSE West, Ireland

5. Antimicrobial Resistance and Healthcare Associated Infections Reference Unit, PHE Colindale, London, United Kingdom

Citation style for this article:

Boo TW, O'Connell N, Power L, O'Connor M, King J, McGrath E, Hill R, Hopkins KL, Woodford N. First report of IMI-1-producing colistin-resistant Enterobacter clinical isolate in Ireland, March 2013. Euro Surveill. 2013;18(31):pii=20548. Available online: http://www.eurosurveillance.org/ViewArticle.aspx?Articleld=20548

Article submitted on 02 July 2013 / published on 01 August 2013

We report the first case in Ireland of an IMI-1 carbapenemase-producing Enterobacter asburiae, which was resistant to both colistin and fosfomycin. The circumstances under which this isolate was acquired were unclear. Several reports of IMI-producing Enterobacter spp. have emerged in recent years, and colistin resistance in Enterobacteriaceae is also increasingly reported. Laboratories should be aware of the unusual antibiograms of IMI-producing isolates.

In late March 2013, a patient was admitted to the Mid-Western Regional Hospital, Limerick, Ireland with fractured ribs. She had not been hospitalised in the previous 24 months; her last hospital stay had been in December 2010.During the admission in 2013, she received a five-day course of amoxicillin-clavulanate for an Escherichia coli urinary tract infection, and routine rectal screening for gastrointestinal carriage of carbapenemase-producing Enterobacteriaceae (CPE) was performed in accordance with the surveillance and infection control policies of the hospital. Carbapenemresistant Enterobacteriaceae were isolated from the culture of the rectal swab. The isolate was identified as Enterobacter asburiae using matrix-assisted laser desorption/ionisation-time of flight (MALDI-TOF) mass spectrometry (BrukerDaltonics, Bremen, Germany) and was designated ME52 in this report.

Antimicrobial susceptibility testing using disc diffusion and gradient minimal inhibitory concentration (MIC)(Etest, BioMerieux, Basingstoke, United Kingdom) methods showed the isolate $M_{52}$ to be resistant to amoxicillin-clavulanate, cefoxitin, ertapenem and meropenem, but susceptible to cefotaxime, ceftazidime, and piperacillin-tazobactam. Among the non-beta-lactam agents, it was susceptible to ciprofloxacin, aminoglycosides and tigecycline. The isolate was resistant to colistin and fosfomycin according to interpretive criteria from the European Committee on Antimicrobial Susceptibility Testing (EUCAST), with MICs of $96 \mathrm{mg} / \mathrm{L}$ and $64 \mathrm{mg} / \mathrm{L}$, respectively [1]. Synergy testing of meropenem with the beta-lactamase inhibitorsboronic acid, dipicolinic acid, and cloxacillin was performed (RoscoDiagnostica, Taastrup, Denmark). Significant potentiation of the meropenem inhibitory zone was observed in the presence of boronic acid, but not with dipicolinic acid or cloxacillin, implying the presence of an Ambler class Acarbapenemase. Realtime PCR for various carbapenemase genes was performed in the Department of Medical Microbiology in Galway University Hospitals, and bla genes for KPC, GES, NDM, VIM, IMP, and OXA-48-like carbapenemases

\section{TABLE}

Antimicrobial susceptibility results of the IMI-producing Enterobacter asburiae ME52 isolated in the Mid-Western Regional Hospital, Limerick, Ireland, March 2013

\begin{tabular}{|l|c|c|}
\hline Antimicrobial agent & MIC (mg/L) & Susceptibility $^{\mathrm{a}}$ \\
\hline Ampicillin & $>64$ & $\mathrm{R}$ \\
\hline Amoxicillin-clavulanate & 64 & $\mathrm{R}$ \\
\hline Piperacillin-tazobactam & 2 & $\mathrm{~S}$ \\
\hline Cefotaxime & 1 & $\mathrm{~S}$ \\
\hline Ceftazidime & 1 & $\mathrm{R}$ \\
\hline Cefoxitin & $>64$ & $\mathrm{~S}$ \\
\hline Aztreonam & 0.25 & $\mathrm{R}$ \\
\hline Ertapenem & 16 & $\mathrm{R}$ \\
\hline Imipenem & 64 & $\mathrm{R}$ \\
\hline Meropenem & 16 & $\mathrm{~S}$ \\
\hline Ciprofloxacin & $\leq 0.125$ & $\mathrm{~S}$ \\
\hline Gentamicin & 1 & $\mathrm{~S}$ \\
\hline Tobramycin & 1 & $\mathrm{~S}$ \\
\hline Amikacin & 2 & $\mathrm{~S}$ \\
\hline Tigecycline & 0.5 & $\mathrm{R}$ \\
\hline Fosfomycin & 64 & $\mathrm{R}$ \\
\hline Colistin & & $\mathrm{S}$ \\
\hline
\end{tabular}

MIC: minimum inhibitory concentration; R, resistant; S, susceptible.

Based on EUCAST interpretive criteria [1]. 
were not detected. The isolate was subsequently referred to Public Health England (PHE) Colindale, London, United Kingdom (UK), for further investigation of the mechanism of carbapenem resistance. PCR identified the presence of $b a_{I M I}$ in $M E_{52}$. Nucleotide sequencing confirmed the carbapenemase to be IMI1. MICs by agar dilution also confirmed susceptibility to third-generation cephalosporins and piperacillintazobactam, as well as resistance to carbapenems and colistin. The Table shows the antimicrobial susceptibility profile (MICs) of the isolate.

On further review, the patient had never received either colistin or fosfomycin therapy in the past. She had travelled in Europe during the past 15 years including France and Italy, but not to the American continent where the first isolates had been reported [2,3]. The only aquatic exposure of note was a visit to the River Jordan in Israel 10 years ago. In the current hospitalisation, the patient made an uneventful recovery and was discharged home.

\section{Discussion}

This is the first report in Ireland of an IMI carbapenemase-producing Enterobacter clinical isolate, coupled with the phenotype of colistin and fosfomycin resistance. It seems that the isolation of ME52 was a chance finding and the period of rectal colonisation by the patient was unknown. The clinical significance of the patient's travel history and aquatic exposure with respect to the acquisition of the IMI-producing $E$. asburiae is unclear.

IMI enzymes, together with another closely related beta-lactamase NMC-A, are found in Enterobacter spp. and form a relatively uncommon group within the Ambler class A carbapenemases [4]. The chromosomally located IMI-1 enzyme was first reported in 1996 in two Enterobacter cloacae isolates in the United States (US) [2]. Subsequently, plasmid-mediated IMI-2 carbapenemase was detected in clonally related environmental $E$. asburiae isolates recovered from seven of 16 rivers in the mid-western regions of the US [3], as well as in an E. cloacae clinical isolate in China [5]. While IMI enzymes are relatively uncommon carbapenemases, their presence in Enterobacter clinical isolates have been reported in recent years in France, Finland and Singapore [6-9]. They consist mainly of E. cloacae isolates producing either the IMI-1 or IMI-2 enzyme. Apart from our current report, IMI-producing $E$. asburiae clinical isolates have also been found in three patients from different cities in France between 2007 and 2011 [9].

To date, the common feature with IMI-producing isolates of the E. cloacae complex is the retention of susceptibility to third-generation cephalosporins such as cefotaxime and ceftazidime, while being resistant to the carbapenems, particularly imipenem. Additionally, IMI-producing $E$. asburiae isolates also retain susceptibility to piperacillin-tazobactam, as shown in the antibiograms of our isolate as well as of those isolated from US rivers from 1999 to 2001 [3].

The finding of a colistin-resistant Enterobacter isolate in a patient without a history of polymyxin therapy is unusual and unexpected. Unlike certain Enterobacteriaceae such as Proteaeor Serratia spp., Enterobacter spp. do not possess intrinsic resistance to colistin [10]. Acquired colistin resistance in Enterobacteriaceae has mainly been reported in Klebsiella pneumoniae, particularly multidrug-resistant clones producing carbapenemases such as KPC enzymes [11-13]. Prior colistin therapy has been documented in some patients, but acquisition of such colistin- and carbapenem-resistant strains in other patients is likely to be the result of cross-transmission in healthcare settings [11-13]. However, a recent study has found unexpectedly high rates of colistin resistance amongst non-multidrug-resistant $E$. cloacae complex isolates from the UK and Ireland [14]. Colistin resistance rates of $6 \%$ and $10 \%$ were found in blood and respiratory isolates, respectively [14]. Fosfomycin is another useful agent for the treatment of multidrugresistant (MDR) Enterobacteriaceae [15]. However, fosfomycin susceptibility rates of Enterobacter spp. were lower than those of $E$. coli or $K$. pneumoniae $[15,16]$. Based on EUCAST interpretive criteria, fosfomycin susceptibility rates ranged from $47 \%$ to $72 \%$ in $E$. cloacae $[16,17]$; while one third of E. asburiae isolates (seven of 21) were resistant to fosfomycin in one European study [17]. Notably, our patient had not received colistin or fosfomycin therapy in the past.

\section{Conclusion}

This is the first report in Ireland of IMI-producing E.asburiae with co-resistance to colistin and fosfomycin. For the accurate detection of IMI-producing Enterobacteriaceae, laboratories should be awareof the unusual antimicrobial resistance profiles of such isolates, particularly if synergy test results with betalactamaseinhibitors suggest the presence of a class $A$ carbapenemase. In the era of mounting antimicrobial resistance and diminishing therapeutic options, laboratories should monitor trends in colistin and fosfomycin resistance amongst Enterobacteriaceae isolates, particularly in Enterobacter spp.

\section{Acknowledgements}

We would like to thank Cathriona Finnegan of the Department of Clinical Microbiology, Mid-western Regional Hospital, Limerick, HSE West for the phenotypic characterisation of the isolate, and Daniele Meunier and Michel Doumith of the Antimicrobial Resistance and Healthcare Associated Infections Reference Unit, PHE Colindale, London, United Kingdom, for performing the nucleotide sequencing of the isolate.

Conflict of interest

None declared. 


\section{Authors' contributions}

Teck-Wee Boo prepared the first and subsequent drafts of the manuscript and collated the clinical and laboratory data. Nuala O'Connell, Margaret O'Connor and Lorraine Power provided the clinical and epidemiological data; while Nuala O’Connell, Joanne King, Elaine McGrath, Robert Hill, Katie Hopkins and Neil Woodford provided relevant sections of laboratory data. All authors read and critically revised the first, subsequent and final drafts of the manuscript.

\section{References}

1. European Committee on Antimicrobial Susceptibility Testing (EUCAST). Breakpoint tables for interpretation of MICs and zone diameters. Version 3.1 EUCAST; 2013. Available from: http://www.eucast.org/clinical-breakpoints/

2. Rasmussen BA, Bush K, Keeney D, Yang Y, Hare R, O'Gara $C$, et al. Characterization of IMI-1 $\beta$-lactamase, a class A carbapenem-hydrolyzing enzyme from Enterobacter cloacae. Antimicrob Agents Chemother. 1996;40(9):2080-6. PMid:8878585 PMCid:PMC163477

3. Aubron C, Poirel L, Ash RH, Nordmann P. Carbapenemaseproducing Enterobacteriaceae, U.S. rivers. Emerg Infect Dis. 2005; 11(2):260-4. http://dx.doi.org/10.3201/eid1102.030684 PMid:15752444 PMCid:PMC3320444

4. Walther-Rasmussen J, Høiby N. Class A carbapenemases. J AntimicrobChemother. 2007;60(3):470-82. http://dx.doi. org/10.1093/jac/dkm226 PMid:17595289

5. Yu YS, Du XX, Zhou ZH, Chen YG, Li LJ. First isolation of blalMI-2 in an Enterobacter cloacae clinical isolate from China. Antimicrob Agents Chemother. 2006;50(4):1610-1. http:// dx.doi.org/10.1128/AAC.50.4.1610-1611.2006 PMid:16569898 PMCid:PMC1426974

6. Naas T, Cattoen C, Bernusset S, Cuzon G, Nordmann P. First identification of blalMI-1 in an Enterobacter cloacae clinical isolate from France. Antimicrob Agents Chemother. 2012;56(3):1664-5. http://dx.doi.org/10.1128/AAC.06328-11 PMid:22203599 PMCid:PMC3294893

7. Österblad M, Kirveskari J, Hakanen AJ, Tissari P, Vaara M, Jalava J. Carbapenemase-producing Enterobacteriaceae in Finland: the first years (2008-11). IntimicrobChemother. 2012;67(12):2860-4. http://dx.doi.org/10.1093/jac/dks299 PMid:22855858

8. Teo JW, La MV, Krishnan P, Ang B, Jureen R, Lin RT. Enterobacter cloacae producing an uncommon class A carbapenemase, IMI-1, from Singapore. J Med Microbiol. 2013;62(Pt 7):1086-8. http://dx.doi.org/10.1099/jmm.0.053363-o PMid:23558141

9. Bernusset S, Naas T, Tande D, Biessy H, Poirel L, Henry M, et al. Characterisation of carbapenemase IMI-2 in Enterobacter spp. clinical isolates from France. Abstr. P1238. 22nd European Congress of Clinical Microbiology and Infectious Diseases (ECCMID), 31 Mar-3 Apr2012, London, United Kingdom.

10. Landman D, Georgescu C, Martin DA, Quale J. Polymyxins revisited. ClinMicrobiol Rev. 2008;21(3):449-65. http:// dx.doi.org/10.1128/CMR.00006-08 PMid:18625681 PMCid:PMC2493081

11. Bogdanovich T, Adams-Haduch JM, Tian GB, Nguyen MH, Kwak EJ, Muto CA, et al. Colistin-resistant, Klebsiella pneumoniae carbapenemase (KPC)-producing Klebsiella pneumoniaebelonging to the international epidemic clone ST258. Clin Infect Dis. 2011;53(4):373-6. http://dx.doi. org/10.1093/cid/cir401 PMid:21810751 PMCid:PMC3202324

12. Kontopoulou K, Protonotariou E, Vasilakos K, Kriti M, Koteli A, Antoniadou E, et al. Hospital outbreak caused by Klebsiella pneumoniae producing KPC-2 $\beta$-lactamase resistant to colistin. J Hosp Infect. 2010;76(1):70-3. http://dx.doi.org/10.1016/j. jhin.2010.03.021 PMid:20705205

13. Mammina C, Bonura C, Di Bernardo F, Aleo A, Fasciana $T$, Sodano C, et al. Ongoing spread of colistin-resistant Klebsiella pneumoniae in different wards of an acute general hospital, Italy, June to December 2011. Euro Surveill. 2012;17(33):pii=20248. Available from: http://www. eurosurveillance.org PMid:22913977

14. Reynolds R, Kidney A, Mushtaq S, and BSAC Extended Working Party on Resistance Surveillance. Surprisingly high prevalence of colistin resistance in Enterobacterspp. in the UK and Ireland. Abstr. P1311. 23rd European Congress of Clinical Microbiology and Infectious Diseases (ECCMID), 27-30 Apr 2013, Berlin, Germany.

15. Falagas ME, Kastoris AC, Kapaskelis AM, Karageorgopoulos DE. Fosfomycin for the treatment of multidrug-resistant, including extended-spectrum $\beta$-lactamase producing,
Enterobacteriaceae infections: a systematic review. Lancet Infect Dis. 2010;10(1):43-50.

16. Lu CL, Liu CY, Huang YT, Liao CH, Teng LJ, Turnidge JD, et al. Antimicrobial susceptibilities of commonly encountered bacterial isolates to fosfomycin determined by agar dilution and disk diffusion methods. Antimicrob Agents Chemother. 2011;55(9):4295-301. http://dx.doi.org/10.1128/AAC.00349-11 PMid:21670185 PMCid:PMC3165352

17. Stock I, Gruger T, Wiedemann B. Natural antibiotic susceptibility of strains of the Enterobacter cloacae complex. Int J Antimicrob Agents. 2001;18(6):537-45. http://dx.doi. org/10.1016/S0924-8579(01)00463-0 